Braz J Med Biol Res, February 2012, Volume 45(2) 93-96

doi: 10.1590/S0100-879X2012007500002

Study of the comprehension of the scientific method by members of a university health research laboratory
A.C. Burlamaque-Neto G.R. Santos, L.M. Lisbôa, J.R. Goldim, C.L.B. Machado, U. Matte and R. Giugliani

The Brazilian Journal of Medical and Biological Research is partially financed by

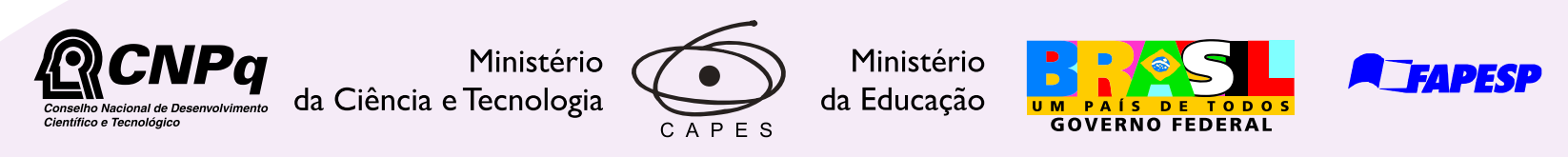

Institutional Sponsors
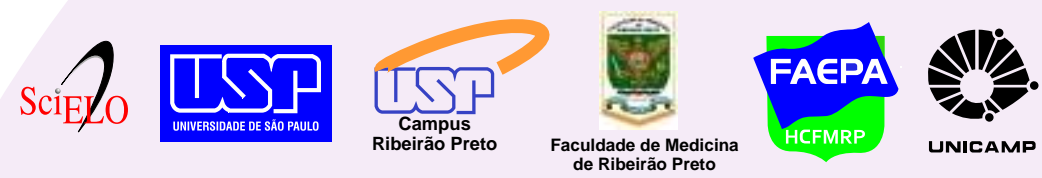

๑ SHIMADZu 


\title{
Study of the comprehension of the scientific method by members of a university health research laboratory
}

\author{
A.C. Burlamaque-Neto ${ }^{1,2}$, G.R. Santos ${ }^{2}$, L.M. Lisbôa², J.R. Goldim4, \\ C.L.B. Machado ${ }^{5}$, U. Matte ${ }^{2}$ and R. Giugliani ${ }^{1,2,3}$ \\ ${ }^{1}$ Programa de Pós-Graduação em Ciências Biológicas: Bioquímica, \\ Universidade Federal do Rio Grande do Sul, Porto Alegre, RS, Brasil \\ ${ }^{2}$ Centro de Terapia Gênica, ${ }^{3}$ Serviço de Genética Médica, ${ }^{4}$ Serviço de Bioética, \\ Hospital de Clínicas de Porto Alegre, Porto Alegre, RS, Brasil \\ ${ }^{5}$ Faculdade de Educação, Universidade Federal do Rio Grande do Sul, Porto Alegre, RS, Brasil
}

\begin{abstract}
In Brazil, scientific research is carried out mainly at universities, where professors coordinate research projects with the active participation of undergraduate and graduate students. However, there is no formal program for the teaching/learning of the scientific method. The objective of the present study was to evaluate the comprehension of the scientific method by students of health sciences who participate in scientific projects in an academic research laboratory. An observational descriptive crosssectional study was conducted using Edgar Morin complexity as theoretical reference. In a semi-structured interview, students were asked to solve an abstract logical puzzle - TanGram. The collected data were analyzed using the hermeneutic-dialectic analysis method proposed by Minayo and discussed in terms of the theoretical reference of complexity. The students' concept of the scientific method is limited to participation in projects, stressing the execution of practical procedures as opposed to scientific thinking. The solving of the TanGram puzzle revealed that the students had difficulties in understanding questions and activities focused on subjects and their processes. Objective answers, even when dealing with personal issues, were also reflected on the students' opinions about the characteristics of a successful researcher. Students' difficulties concerning these issues may affect their scientific performance and result in poorly designed experiments. This is a preliminary study that should be extended to other centers of scientific research.
\end{abstract}

Key words: Scientific method; Complexity; Academic scientific research

\section{Introduction}

In Brazil, scientific research is carried out mainly at universities, where professors coordinate research projects that are conducted with the active participation of undergraduate and graduate students. Classes and courses dedicated to the teaching of the scientific method have been excluded from the curricula of undergraduate and graduate health sciences. They have been replaced by the study of "scientific methodology", which concerns how to write and carry out a research project. Science history and philosophy, as well as the study of the scientific method, are either overviewed in a very superficial manner or absent. Thus, students arrive at laboratories or centers of scientific research without going through a systematization of the knowledge related to the scientific method.
Such learning takes place at these sites of scientific research, focused on practical issues. Learning scientific research procedures mainly occurs in a process divided into three phases. First, a researcher experienced in a given procedure provides theoretical explanations to the beginner. In the second phase, the beginner observes the more experienced researcher, who carries out the procedure. Besides the influence of previous experiences, the critical sense of the beginner is fostered by the first phase. In the third phase, the procedure is carried out by the beginner, supervised by the experienced researcher. This phase is also influenced by other experiences and by the previous phases. From this point on, beginners are considered to be able to start carrying out the procedure on their own.

Correspondence: R. Giugliani, Serviço de Genética Médica, Hospital de Clínicas de Porto Alegre, Rua Ramiro Barcelos, 2350, 90035-903 Porto Alegre, RS, Brasil. E-mail: rgiugliani@hcpa.ufrgs.br

Received August 3, 2011. Accepted December 14, 2011. Available online January 20, 2012. Published February 17, 2012. 
This educational process is informal, and the current science educational model does not make demands regarding its systematizations by means of formal teaching/learning processes. On the other hand, there are requirements for the conclusion of undergraduate and graduate courses, such as course completion projects and presentation of dissertations and theses. At this point, students are required to comprehend the scientific method and to carry out a scientific research study without having been formally taught to do so. At the end of the course, it is assumed that the students learned because they have produced written material, although their comprehension of the scientific method is not really known.

The objective of the present study was to analyze the comprehension of the scientific method by students of health sciences at an academic research laboratory. Since the study focused on the students, its execution required taking into consideration both the subjects (the individuals involved) and the processes. To this end, we used Edgar Morin complexity (1) as the theoretical reference. Studying the understanding of the scientific method by students should lead to a better understanding of the informal process of teaching/learning the scientific method that takes place in research laboratories.

\section{Material and Methods}

The study was carried out at the Centro de Terapia Gênica (CTG) of Hospital de Clínicas de Porto Alegre (HCPA), the teaching hospital of Universidade Federal do Rio Grande do Sul (UFRGS). The experimental design used was an observational descriptive cross-sectional study (2).

The theoretical reference used was Edgar Morin complexity, considering that the academic space of scientific research consists of different and inseparable components that compose a whole and that there is an interdependent and interactive tissue that relates this whole with its parts $(1,3)$. A semi-structured interview script was prepared to assess the knowledge of the respondents about the scientific method.

The study was approved by the Research Ethics Committee of HCPA (reference No. 07-611) and the subjects interviewed gave written informed consent to participate. Total confidentiality was requested from the participating students as to the content of the interviews, which had their audios recorded and included the solving of the TanGram, an abstract logical puzzle. This is a Chinese game composed of 7 pieces that may be used to form a large range of figures. The following rules were adopted: all pieces must be used, all pieces must touch at least one other piece, and the figure must represent something concrete that the respondent can name. The interviews were always held in the same place by the same interviewer (G.S.) who had received specialized training.
The data were analyzed using the hermeneutic-dialectic analysis method proposed by Minayo (4). Only students who were currently linked to or who had been previously linked to the laboratory were interviewed. To organize the data, the authors listened to the recordings, transcribed the interviews, and examined the observations reported by the interviewer. Data were classified according to three different categorical divisions: by respondent, by question and by theme. The final analysis considered the data from the point of view of complexity.

\section{Results}

The interviews began with identification questions that were prepared to set the mood of the respondent and to introduce the subject. A total of 18 students were interviewed, 8 of them undergraduates, 4 Master's students, and $6 \mathrm{PhD}$ students. Their undergraduate courses were Biology, Pharmacy, Biomedicine, and Medicine. Master's and PhD students were associated with graduate courses in biological and health sciences, and 8 of these graduate students had also participated in scientific research when undergraduates.

A setting of spontaneous informality marked the interviews, probably due to the fact that the interviewer was a former laboratory colleague of the respondents, to the academic environment, and to the personal characteristics of the group. All respondents agreed to answer the questions and only one refused to solve the logic puzzle. The duration of the interviews ranged from 15 to $60 \mathrm{~min}$. The themes exposed by the respondents were varied and were analyzed according to the theoretical reference of the study, i.e., Edgar Morin complexity $(1,3)$.

The first question presented to the respondents was "What do you understand as the scientific method?". The answers did not meet the concept presented by the scientific literature on the theme, but were related to the scientific activities of the respondents in the laboratory, i.e., being involved in scientific projects. Indeed, the answers to this question were consistent with the notion of a scientific project much more than that of the scientific method. One of the respondents said: "You must have an objective, you must have a hypothesis, you have to have your own method, then you will evaluate which methodologies are used in the scope of science according to what you are analyzing, and then you have to reach a conclusion."

Interviews proceeded with the question "Do you consider it important to know authors related to the scientific method? Why? In case of an affirmative answer, which one(s)?" Students think it is important to know these authors; however, in general, they are not able to mention any. The authors related to the scientific method were mistaken for researchers that standardize techniques, authors of scientific articles, and researchers who made important contributions to science or were pioneers in certain fields. 
However, even these were rarely mentioned.

The following question of the interview script, "Solve a logic puzzle (TanGram) and report what you used from your research experience in this situation. In case you do not want to solve the puzzle, report a research experience you had.", aimed to include a process in which the relationship between subject and object occurs. This game highlighted the subjectivity of the respondents within the context of the interviews. Before beginning, respondents were asked about their previous knowledge of the game.

Only 2 of 18 already knew the TanGram. Requests for repeated explanations about the rules were frequent, as well as declarations by many respondents that they lacked creativity and that the game was difficult - even though at this point there were still no attempts to solve it. During the process, questions about the remaining time and concerns regarding the evaluation of the figure they were about to form were recurrent, although the interviewer never made any comments about time limit or figure evaluation. Only one respondent did not want to play and two showed figures that did not represent anything concrete. The remaining 15 went through the process as specified by the rules.

When respondents claimed their figure was finished, the interviewer asked a series of five questions related to the process. The first question consisted of asking the respondent the meaning of the figure, thus beginning a conversation about TanGram. Some respondents had already provided this information before the question was asked. Next, the interviewer asked why the respondent had constructed that figure, inducing the respondent to describe the assembling process. Regarding this aspect, the respondents could be divided into two main groups: those who had a previous idea, but ended up with something different, and those who kept moving the pieces without a previous idea until they could see something in a determined position. Only one individual assembled the pieces according to her previous idea.

The third question about the process concerned how respondents had felt. Instead of talking about their feelings, respondents mainly commented about the game: "It was difficult."; "It's interesting."; "It needs thinking." Respondents then made comments about themselves that in a general way conveyed the idea that they had no creativity or imagination. The interviewer would then ask whether it would make any difference if she had told them what figure to assemble. The prevailing idea was that it would be easier if one knew what to assemble, although this would hinder creativity. Finally, the respondents were asked to relate TanGram to their laboratory research, a question, which at first, was not understood. However, respondents soon started to point out common aspects, with creativity itself being one of the prevailing themes. There was a general idea that creativity is a gift for a few lucky persons, and not something that everyone makes use of on a day-today basis. On the other hand, although most students claimed that they were not creative and lacked imagination, they stated that both TanGram and scientific research demanded creativity. However, there was also a general notion that creativity is hindered by the objectivity required of researchers: "Creativity is something I try to apply to my research, but it is not always possible, because I have to keep my focus and objectivity. While playing TanGram, I can be inconsistent."

The interview ended with the following question: "In your opinion, what are the characteristics of a successful researcher?" The answers were marked by a list of characteristics and virtues. For instance: "to like what one does; to like studying; to be dedicated; to want to grow, go for it, and make progress; to accept other people's opinions." All respondents answered this question in a similar manner.

\section{Discussion}

In modern and contemporary times, various schools of thought have produced a wide variety of conceptualizations and designs for scientific activities. Comprehension of the scientific method involves reflections and thoughts about the purposes and objectives of science, as well as its precepts and principles. The scientific project, in turn, is the operationalization of the study of a scientific issue, involving a specific application of the scientific method, but it is not the method itself. However, techniques, protocols, and procedures are the themes that mainly appeared in the answers given by the students when asked about the scientific method. Since their practice in scientific research is based on participation in projects, and since there is no educational process concerning the scientific method, it is natural that the students would evoke what they know about doing science, i.e., the themes related to scientific projects, in order to answer this question.

This reduction of the students' knowledge to what could be called "operative science" excludes scientific thinking and reflections about science itself. As a consequence, the notion about scientific projects is also limited to their specific area and particular manners of carrying out projects. Scientific knowledge, in turn, is restricted to what is necessary in order to complete a project.

Lack of knowledge about schools of scientific thought, little reflection about science, and non-articulation between science thinking and scientific research laboratory practice are thereby confirmed in the question about authors. Despite the strong influence of Cartesianism on our science, René Descartes was mentioned by only 2 of 18 students. Students not only ignored the authors related to the scientific method, mistaking them for researchers in general, but they were also unable to mention researchers who have made fundamental contributions to their field of work.

The issue regarding the achievement of a desired result by means of a research project was pointed out when the students related TanGram to their science practice. 
Respondents claimed that scientific research brings about the unexpected and one must know how to deal with that. However, "unexpected" refers here to not reaching the expected result, as if there was a right answer previously established for the experiments and projects. The concern with the evaluation of the figure - although the interviewer did not mention any evaluation - is also based on the idea that there is a right answer. It seems that the respondents understand their science practice mainly as the participation in projects for which the desired results have been previously identified.

The answer to the final question was a list of "virtues". The students did not mention any themes related to the professional objectives, motivations, and purposes of a successful researcher. Also, the researcher's career was not put in context with external factors such as science, society, or nature (5). The subjectivity of the scientist was treated objectively, as if the sum of the positive characteristics were enough to guarantee success, with commitment being the most relevant. According to this point of view, every researcher would be able to reach success in science. Contradictorily, creativity was also mentioned as a characteristic of successful researchers, although it is seen as a gift that only a few have.

Comprehension of the scientific method by the students who carry out scientific research is fundamental for their educational autonomy (6). Nevertheless, a science educational process that excludes science history and philosophy, limiting students' learning to operational procedures, leads to reduced comprehension of science itself (the principles of the scientific method, for example) and its relation to society (context and purpose of scientific activities). Current students' difficulties concerning these issues also affect their science operationalization, since misunderstanding of basic concepts such as "hypothesis" may result, and actually does

\section{References}

1. Morin E. Seven complex lessons in education for the future. Paris: Unesco Publishing; 1999.

2. Goldim JR. Manual de iniciação à pesquisa em saúde. 2nd edn. Porto Alegre: Dacasa; 2000.

3. Morin E. A cabeça bem-feita: repensar a reforma, reformar o pensamento. 12th edn. Rio de Janeiro: Bertrand Brasil; 2006.

4. Minayo MCS. O desafio do conhecimento - pesquisa qualitativa em saúde. 4th edn. São Paulo: Hucitec; 1996. result, in poorly designed experiments.

This is a preliminary study that should be extended to other centers of scientific research. The authors offer help to groups willing to repeat this study at their centers. In addition, other actions would include the analysis of the experimental designs of scientific projects submitted to research ethics committees or funding agencies to evaluate the consequences of the situation described here. Moreover, editors of scientific journals could also contribute by evaluating these aspects in manuscripts submitted for publication, regardless of their acceptance status. These analyses would assess whether the projects or papers show clear elucidation of research questions, appropriate definitions of the study design, the relationship between the results presented and the conclusions reached (if applicable), and others.

The results presented here should be placed in perspective. The reduction of science comprehension by students to operational procedures is part of a complex scenario, which is influenced by several aspects of today's society. The gap between doing science and the resulting technologies has become practically inexistent, replaced by the so-called technoscience (7). The tension between developing processes and accomplishing related products, globalization, and the speed of information, all dictate the increasing needs of current science to move faster and to deliver immediate results. Through this study on the comprehension of the scientific method by students, we explored a theme that allows reflecting about and understanding science as it is today.

\section{Acknowledgments}

The authors are grateful to the participating students. Research supported by CNPq, FAPERGS, and FIPE-HCPA.

5. Meis L, Rangel D. O porquê do projeto. Ensinando ciência com arte. Volume 2 [DVD]. Rio de Janeiro: Departamento de Bioquímica Médica, UFRJ; 2002.

6. Freire P. Pedagogia da autonomia: Saberes necessários à prática educativa. São Paulo: Paz e Terra (Colecção Leitura); 1997.

7. Hottois G. Le signe et la technique. La philosophie à l'épreuve de la technique. Paris: Aubier Montaigne; 1984. 